\title{
Surgical Treatment of Left Ventricular Pseudoaneurysm
}

\author{
Emir Mujanovic ${ }^{1}$, Jacob Bergsland ${ }^{1,2}$, Sevleta Avdic ${ }^{1}$, Sanja Stanimirovic-Mujanovic ${ }^{1}$, \\ Tamara Kovacevic-Preradovic ${ }^{3}$, Emir Kabil ${ }^{1}$
}

\author{
BH Heart Center Tuzla, Tuzla, Bosnia and Herzegovina ${ }^{1}$ \\ The Intervention Centre, Oslo University Hospital, Oslo Norway ${ }^{2}$ \\ Clinic for cardiovascular diseases, Clinical Center Banja Luka, Bosnia and Herzegovina ${ }^{3}$
}

Corresponding author: prof Emir Mujanovic, MD, PhD. BH Heart Center Tuzla, Alekse Santica 8, Tuzla, Bosnia and Herzegovina, Phone: 035309 140, 035309 149, Email: emirmujanovic2@gmail.com

\begin{abstract}
Introduction: Left ventricular pseudoaneurysm is a rare condition because in most instances ventricular free-wall rupture leads to fatal pericardial tamponade. Rupture of the free wall of the left ventricle is a catastrophic complication of myocardial infarction, occurring in approximately $4 \%$ of patients with infarcts, resulting in immediate collapse of the patient and electromechanical dissociation. In rare cases the rupture is contained by pericardial and fibrous tissue, and the result is a pseudoaneurysm. The left ventricular pseudoaneurysm contains only pericardial and fibrous elements in its wall-no myocardial tissue. Because such aneurysms have a strong tendency to rupture, this disorder may lead to death if it is left surgically untreated. Case report: In this case report, we present a patient who underwent successful repair of a left ventricular pseudoaneurysm, which followed a myocardial infarction that was caused by occlusion of the left circumflex coronary artery. Although repair of left ventricular pseudoaneurysm is still a surgical challenge, it can be performed with acceptable results in most patients.
\end{abstract}

Key words: left ventricular pseudoaneurysm, surgical repair.

\section{INTRODUCTION}

Left ventricular pseudoaneurysm (LVP) is a very rare condition because in most instances ventricular free-wall rupture leads to fatal pericardial tamponade (1). Myocardial infarction (MI) is the most common cause of false aneurysms of the left ventricle $(2,3)$. Rupture of the free wall of the left ventricle is most often catastrophic complication of MI, occurring in approximately $4 \%$ of patients with infarcts resulting in immediate collapse of the patient (4). In addition, it may be associated with mitral valve replacement, previous unsuccessful ventriculotomy, trauma, inflammation, tumor invasion, and apical venting (5).

LVP develop when pericardium surrounds the rupture in combination with thrombus and inflammation and thus prevents the development of a hemopericardium. It contains only pericardial and fibrous elements in its wall, with no myocardial tissue. LVP may remain silent unless it gives rise to hemopericardium, once the hemopericardium develops, it may result in cardiac tamponade and sudden death (6). Because such aneurysms have a strong tendency to rupture, this disorder may lead to death if it is left surgically untreated (7).

In this case report, we present a patient who underwent successful repair of a LVP, which followed a myocardial infarction that was caused by occlusion of the left circumflex coronary artery.

\section{PATIENT AND METHOD}

A 57-year-old male patient was admitted to another hospital with chest pain that had started 7 days previously. During coronary angiography, selective left coronary injection with showed occlusion of the distal left circumflex artery.(Figure 1). The ventriculography is shown in Figure 2, demonstrating what appears to be an aneurysm.

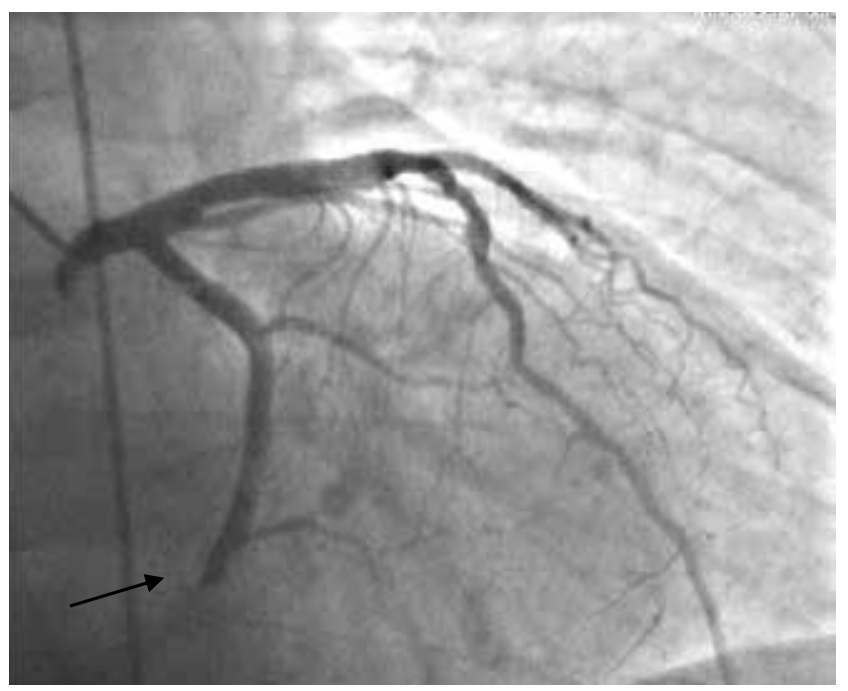

Figure 1. Coronary angiography: occlusion of the left circumflex artery in its distal portions 


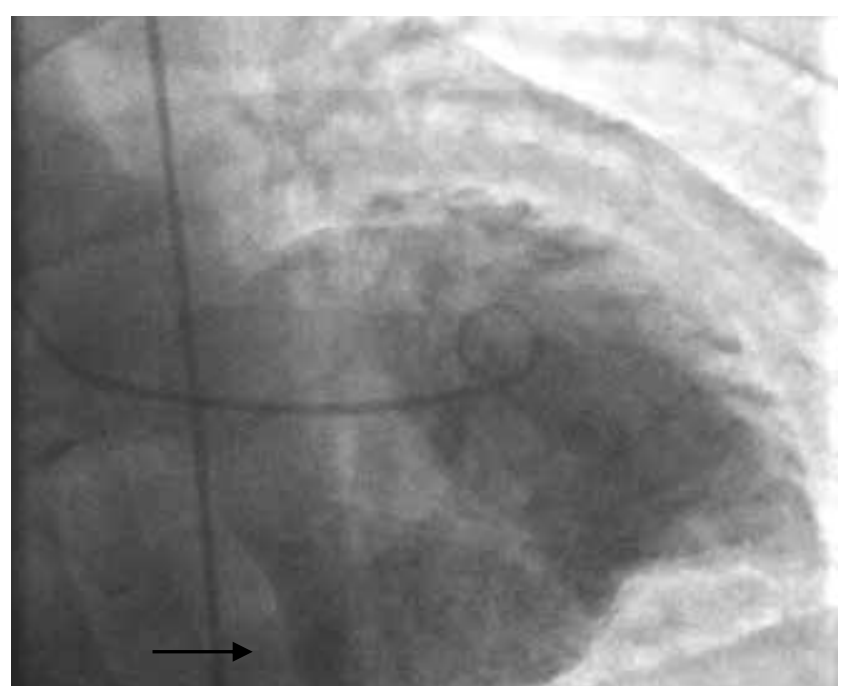

Figure 2. Ventriculography: left ventricular pseudoaneurysm in the inferobasal wall.

Echocardiography showed LV dysfunction with an ejection fraction of 0.35 and akinesia of the inferior wall. On this echo it became apparent that the patient had a large LVP measuring around $5 \times 5 \mathrm{~cm}$ on the inferobasal wall, communicating through a narrow neck of $2,2 \mathrm{~cm}$ in diameter (Figure 3).

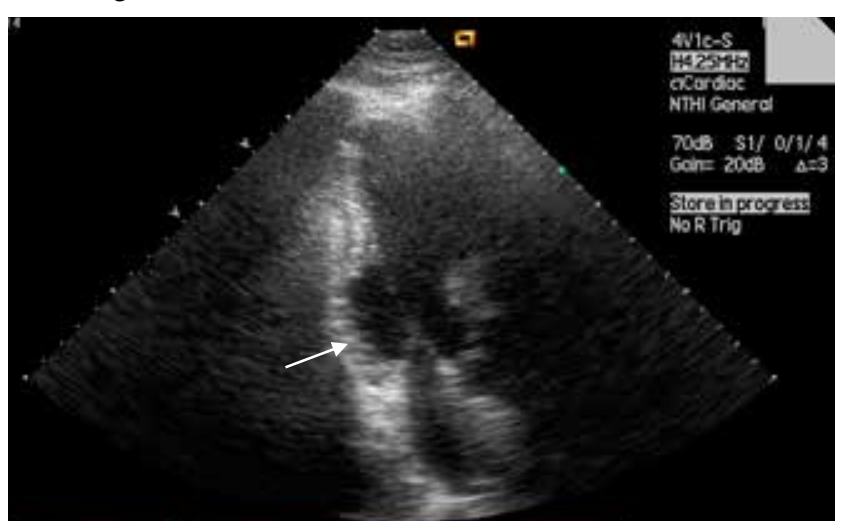

Figure 3. Echocardiography: large left ventricular pseudoaneurysm in the inferobasal wall

Intraoperatively, a large non ruptured posterior pseudoaneurysm was seen to communicate through a the neck which measured $2 \times 3 \mathrm{~cm}$ in diameter. It was located beneath the posterior papillary muscle (Figure 4). The LVP

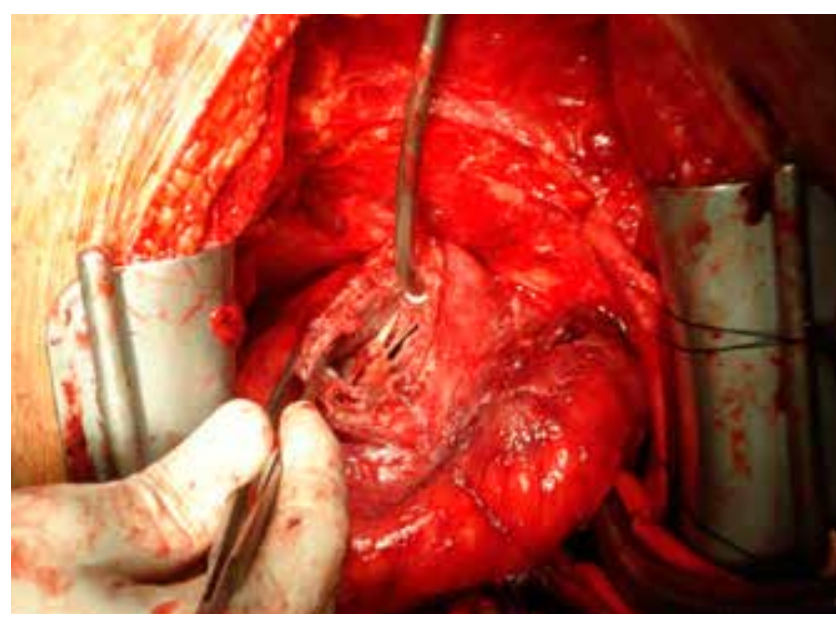

Figure 4. Intraoperative finding: opened left ventricular pseudoaneurysm

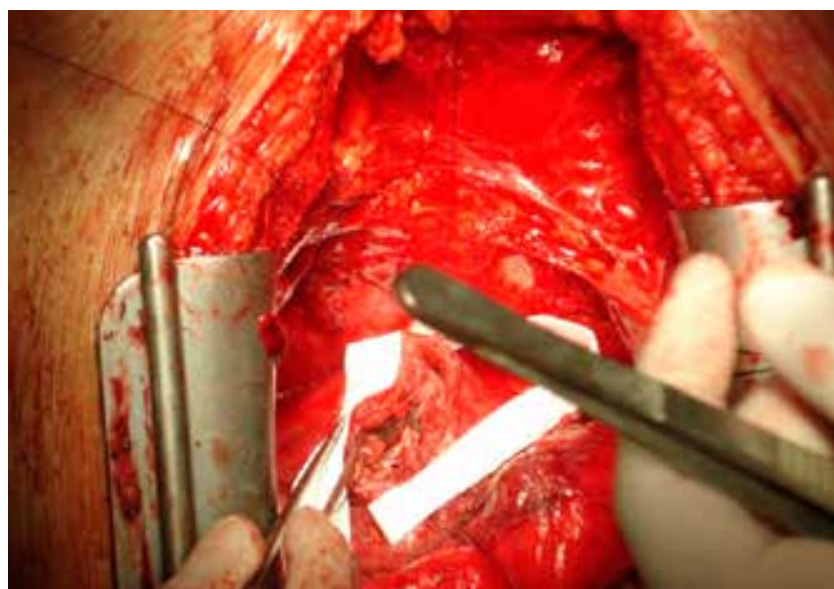

Figure 5. Rapair of defect with dacron patch

was resected, and the defect in the inferior wall of the left ventricle repaired with a Dacron patch (Figure 5).

The postoperative course was uneventful. An echocardiogram on the third postoperative day showed improvement in ejection fraction to 0.50 , and the repair site was clearly seen (Figure 6). There was a minimal mitral regurgitation. At the 6-months follow-up visit, the patient was in NYHA Class I.

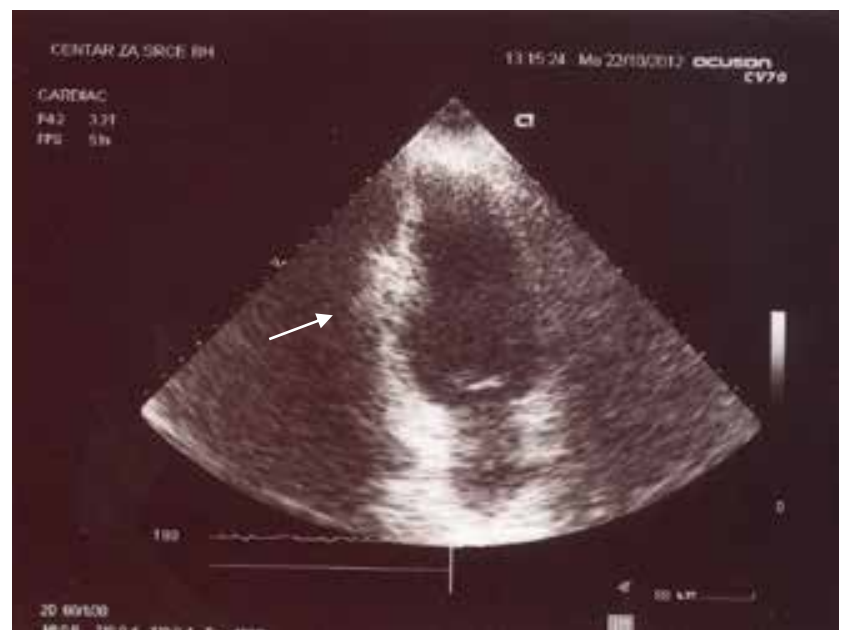

Figure 6. Postoperative echocardiography after pseudoaneurysm repair

\section{DISCUSSION}

LVP is rare with a prevalence of $0.05 \%$ (8), and usually develops in patients having their first MI (9). Inferior and posterolateral MI are responsible for $82 \%$ of the LVP developing after MI. Usually, LVP is located inferoposterior due to occlusion of the circumflex artery, but it can be found in the apical region due to anterior MI. Anterior MI rarely results in LVP formation because ruptures in the anterior wall generally leads to hemopericardium or tamponade $(10,11)$. LVP may remain clinically silent and be discovered during routine clinical investigations, or can present with chest pain, congestive heart failure, arrhythmias, or embolism. The development of heart failure is related to an non contracted and dyskinetic region, with dilatation of the pseudoaneurysm sac during systole. Fatal rupture, hemopericardium, and tamponade are important complications of pseudoaneurysm. The risk of acute complications is higher in the first 3 months after MI. LVP are associated with a mortality rate approaching $50 \%$. This 
is mainly due to rupture, thromboembolism or ventricular arrhythmia (12).

Cardiac catheterization with left ventriculography has been the gold standard for establishing the diagnosis, and is necessary before surgery to evaluate the need for concomitant bypass grafting (13). In addition, Echocardiography is an alternative imaging modality (14).

There is strong indication for surgery in LVP (15) since untreated pseudoaneurysm have a $30 \%$ to $45 \%$ risk of rupture (16). The general consensus is that surgery is indicated for all patients as soon as the diagnosis is established, unless the surgical risk is prohibitive. If a pseudoaneurysm is diagnosed within 2 to 3 months after MI, emergency surgery should be performed because of the high risk of rupture. If the diagnosis is made years after MI, the necessity and urgency of surgery depends on the symptoms. LVPs smaller than $3 \mathrm{~cm}$ detected incidentally, may be managed conservatively. Resection, if necessary, combined with bypass grafting is the treatment of choice in symptomatic patients, but the operative risk is high due $(7 \%-29 \%)$ to the underlying cardiac pathologies (17).

\section{CONFLICT OF INTEREST: NONE DECLARED}

\section{REFERENCES}

1. Vlodaver Z, Coe JI, Edwards JE. True and false left ventricular aneurysms. Propensity for the latter to rupture. Circulation. 1975; 51: 567-572.

2. Csapo K, Voith L, Szuk T, Edes I, Kereiakes DJ. Postinfarction left ventricular pseudoaneurysm. Clin Cardiol. 1997; 20: 898-903.

3. Hung MJ, Wang CH, Chang WJ. Unruptured left ventricular pseudoaneurysm following myocardial infarction. Heart. 1998; 80: 94-97.

4. Falcao JL, Falcao SN, Garcia MF, Arruda AL, Hueb AC. et al. Left ventricular pseudoaneurysm associated to severe mitral insufficiency, complicating inferolaterodorsal acute myocardial infarction. Arq Bras Cardiol. 2005; 84: 488-491.

5. Moreno R, Gordillo E, Zamorano J, Almeria C, Garcia-Rubira
JC. et al. Long term outcome of patients with postinfarction left ventricular pseudoaneurysm. Heart. 2003; 89: 1144-1146.

6. Treasure T. False aneurysm of the left ventricle [editorial]. Heart. 1998; 80: 7-8.

7. Malcolm ID, Fitchett DH, Stewart D, Marpole D, Symes J. Ventricular aneurysm: false or true? An important distinction. Ann Thorac Surg. 1980; 29: 474-477.

8. Mahilmaran A, Nayar PG, Sheshadri M, Sudarsana G, Abraham KA. Left ventricular pseudoaneurysm. Tex Heart Inst J. 2002; 29: 122-125.

9. Yeo TC, Malouf JF, Oh JF, Seward JB. Clinical profile and outcome in 52 patients with cardiac pseudoaneurysm. Ann Intern Med. 1998; 128: 299-305.

10. Eren E, Bozbuga N, Toker ME, Keles C, Rabus MB, Yildirim O. et al. Surgical treatment of post-infarction left ventricular pseudoaneurysm: a two-decade experience. Tex Heart Inst J. 2007; 34: 47-51.

11. Brown SL, Robert JG, Harris GM. Distinguishing left ventricular aneurysm from pseudoaneurysm. A review of the literature. Chest. 1997; 111: 1403-1409.

12. Hung MJ, Wang $\mathrm{CH}$, Chang WJ. Unruptured left ventricular pseudoaneurysm following myocardial infarction. Heart. 1998; 80: 94-97.

13. Roelandt JR, Sutherland GR, Yoshida K, Yoshikawa J. Improved diagnosis and characterization of left ventricular pseudoaneurysm by Doppler color flow imaging. J Am Coll Cardiol. 1988; 12: 807-811.

14. Catherwood E, Mintz GS, Kotler MN, Parry WR, Segal BL. Two-dimensional echocardiographic recognition of left ventricular pseudoaneurysm. Circulation. 1980; 62: 294-303.

15. Komeda M, David TE. Surgical treatment of postinfarction false aneurysm of the left ventricle. J Thorac Cardiovasc Surg. 1993; 106: 1189-1191.

16. Atik FA, Navia JL, Vega PR, Gonzalez-Stawinski GV, Alster JM, Gillinov AM. et al. Surgical treatment of postinfarction left ventricular pseudoaneurysm. Ann Thorac Surg. 2007; 83: 526-531.

17. Daglar B, Celkan MA, Kazaz H, Ustunsoy H, Davutoglu V. Surgical treatment of postinf arction left ventricular pseudoaneurysm. J Card Surg. 2004; 19: 544-546. 